\title{
ANTITHROMBOTIC ACTIVITY OF TAMARINDUS INDICA L. IN MICE
}

\author{
FADLINA CHANY SAPUTRI ${ }^{*}$, CHAVELLA AVATARA ${ }^{2}$, DIAN RACHMAWATI ${ }^{1}$
}

${ }^{1}$ Department of Pharmacology, Faculty of Pharmacy, Universitas Indonesia, Depok 16424, Indonesia. ${ }^{2}$ Drug Development Laboratory, Faculty of Pharmacy, Universitas Indonesia, Depok 16424, Indonesia. Email: fadlina.chany@farmasi.ui.ac.id

Received: 05 May 2018, Revised: 20 September 2018, Accepted: 15 November 2018

ABSTRACT

Objective: This study aimed to investigate the antithrombotic activity of Tamarindus indica L. extract (TIE) in mouse models (in vivo).

Methods: TIE was orally administered to mice at three different doses for 7 days. TIE-treated mice were used in two experiments of antithrombotic activity: An examination of bleeding time following tail cutting and an examination of survival rate after collagen-epinephrine-induced thromboembolism. The TIE groups were observed after 7 days of treatment and compared to an aspirin-treated group and a control group.

Results: Treatment with TIE led to a significant increase in bleeding time compared with that in the control group. TIE treatment also protected mice from thromboembolic death, significantly increasing survival rates in a dose-dependent manner.

Conclusion: TIE has the potential as an antithrombotic agent against platelet thromboembolism.

Keywords: Antithrombotic, Bleeding time, Survival rate, Tamarindus indica L.

(C) 2018 The Authors. Published by Innovare Academic Sciences Pvt Ltd. This is an open access article under the CC BY license (http://creativecommons. org/licenses/by/4. 0/) DOI: http://dx.doi.org/10.22159/ijap.2018.v10s1.08

\section{INTRODUCTION}

Thrombosis, as one of the risk factors of cardiovascular disease, is the formation of a blood clot in an artery or a vein which starts with platelet aggregation $[1,2]$. Deep vein thrombosis (DVT) refers to the formation of one or more blood clots in one of the major blood vessels of the body, most commonly in the lower limbs. The most serious complication that can arise from DVT is a pulmonary embolism (PE), which occurs in more than one-third of patients with DVT and often causes sudden death [3-5]. Acetylsalicylic acid (ASA), commonly known as aspirin, is often used as a platelet aggregation inhibitor agent. ASA inhibits platelet aggregation by inhibiting the cyclo-oxygenase (COX) enzyme within the COX pathway, thus preventing thrombus formation [6]

In addition to chemical drugs, herbal medicines have been studied for their potentials as the antithrombotic agent. Tamarind (Tamarindus indica L.), a flowering plant within the family Fabaceae, is a potential antithrombotic agent due to its active compound dotriacontanoic acid [7]. This compound is one component of D-003, a natural compound comprising triacontanoic, dotriacontanoic, and tetradecanoic acid [8,9]. Compound D-003 has been tested in vitro on a venous thrombosis model; a dose of $200 \mathrm{mg} / \mathrm{kg}$ has shown to increase the number of prostacyclin molecules (prostaglandin $\left.\mathrm{I}_{2}\left[\mathrm{PgI}_{2}\right]\right)$ and reduce thromboxane $\mathrm{A} 2\left(\mathrm{TxA}_{2}\right)$. In vivo experiments with $\mathrm{D}-003$ have demonstrated that this compound can reduce the formation of venous thrombus at a dose of $400 \mathrm{mg} / \mathrm{kg}$ in collagen-induced and epinephrine-induced mice [8]. In this study, the effects of T. indica L. extract (TIE) were tested in vivo on mice using bleeding time and survival rate as metrics of antithrombotic activity.

\section{MATERIALS AND METHODS}

Materials

Ethanolic TIE was obtained from the Indonesian Spice and Medicinal Crops Research Institute, Bogor. This study used aspirin (Medifarma, Indonesia) as a positive control. Carboxymethyl cellulose (CMC) $(0.5 \%$; Brataco, Indonesia) and saline (Euro-Med, Indonesia) were used as a vehicle group (normal and negative control group). Voucher specimens were deposited at the Center for Plant Conservation Botanic Gardens (No. B-1693/IPH.3./KS/VI/2017).
Total flavonoid and phenolic content assays

Total flavonoid content was measured using the aluminum chloride colorimetry method, with absorbance measured at $\lambda=510 \mathrm{~nm}$ [10]. The total phenolic compound content was measured using the FolinCiocalteu method, with absorbance measured at $\lambda=725 \mathrm{~nm}$ [11].

\section{Animals}

Male mice (Mus musculus, ddY strain) weighing between 20 and $30 \mathrm{~g}$ were obtained from the Institute Pertanian Bogor. The use of animals in this study was approved by the Ethics Committee of Faculty of Medicine, Universitas Indonesia (Number. 232/UN2.F1/ETIK/2017).

\section{Antithrombotic activity tests}

Bleeding time test

The treatment of bleeding time was determined according to protocols described by Saputri et al. (2017) with the following modifications. Mice were divided into the treatment groups shown in Table 1 and acclimatized for 1 week. Experimental treatment doses were given to mice through oral administration for 7 days. The dose of aspirin applied was $80 \mathrm{mg} /$ day [12-14]. Experimental TIE doses were 14, 28 , and $56 \mathrm{mg} / 20 \mathrm{~g}$ mice. Antithrombotic activity was evaluated by a bleeding time of $5 \mathrm{~h}$ after experimental day 7. The animals were anesthetized with ether by inhalation and placed in a horizontal position. An approximately $10-\mathrm{mm}$ segment of the tail was amputated from each animal using a scalpel. The end of each severed tail was immediately immersed in a $15 \mathrm{~mL}$ Falcon tube containing isotonic saline. The remaining portion of the tail was vertically positioned with the tip horizontally placed approximately $2 \mathrm{~cm}$ below the body. Bleeding observations were conducted for 20 min [12]. Differences in bleeding time with TIE treatment were obtained by comparing each experimental dosage group to the vehicle group.

\section{Survival rate test}

Mice used for survival rate tests were divided into treatment groups as shown in Table 2. The survival rate tests were performed $24 \mathrm{~h}$ after experimental day 7. To induce pulmonary thrombosis, experimental mice were injected with a mixture of collagen $(700 \mu \mathrm{g})$ and epinephrine $(42 \mu \mathrm{g})$ 
Table 1: Treatment groups used for tests of bleeding time in mice

\begin{tabular}{lllll}
\hline Group & Number of mice $(\mathbf{n})$ & Dosage $(\mathbf{m g} / \mathbf{2 0} \mathbf{g}$ mice) & Bleeding time treatment \\
\cline { 4 - 5 } & & & Days 1-7 & CMC 0.5\% \\
\hline Normal & 5 & & Aspirin & Tail bleeding assay \\
ASA & 5 & 0.208 & Tamarind extract (TIE) \\
Dose 1 & 5 & 14 & \\
Dose 2 & 5 & 28 & \\
Dose 3 & 5 & 56 & \\
\hline
\end{tabular}

CMC: Carboxymethyl cellulose, ASA: Acetylsalicylic acid

Table 2: Treatment of survival rate in mice

\begin{tabular}{llll}
\hline Group & Number of mice (n) & Dosage (mg/20 g mice) & Survival rate treatment \\
\cline { 3 - 4 } & & & Day 1-7 \\
\hline Normal & 5 & & CMC 0.5\% \\
Negative & 5 & & CMC 0.5\% \\
ASA & 5 & 0.208 & Aspirin \\
Dose 1 & 5 & 14 & Tamarind extract (TIE) \\
Dose 2 & 5 & 28 & Thrombotic Injection \\
Dose 3 & 5 & 56 & \\
\hline
\end{tabular}

CMC: Carboxymethyl cellulose, ASA: Acetylsalicylic acid

in the vein of the tail $[12,15]$. Control mice were administered an injection of an isotonic saline solution. After $15 \mathrm{~min}$, the number of dead or paralyzed mice was recorded and the survival rate was calculated as follows:

\section{(1 - [number of dead or paralyzed mice]/total number of mice) $\times 100$}

The increase in survival rate with TIE treatment was analyzed by comparing the survival rates of each experimental dosage group to that of the vehicle group [12].

\section{Statistical analyses}

Analyses were performed using the statistical software SPSS (v.18). Homogeneity of the data was tested using the Levene method and normality was confirmed using the Shapiro-Wilk method. Normally distributed and homogeneous data were analyzed using one-way ANOVAs to assess the overall differences among experimental groups. Pairwise differences between groups were then examined using least significant difference analysis.

\section{RESULTS AND DISCUSSION}

Total flavonoid and phenolic content assays

The TIE had a low flavonoid content of $0.002 \%$ with no detectable phenolic content.

\section{Bleeding time}

Compared to the vehicle group, mice treated with single oral doses of TIE exhibited significantly increased bleeding times $(p \leq 0.05)$. The experimental group treated with the lowest TIE dose ( $14 \mathrm{mg} / 20 \mathrm{~g}$ mice) exhibited a $99 \%$ increase in bleeding time compared to the vehicle group. Mice treated with higher TIE doses ( 28 and $56 \mathrm{mg} / 20 \mathrm{~g}$ mice) exhibited increases in bleeding time of $118 \%$ and $128 \%$, respectively, compared to the vehicle group. The effects of TIE treatments were qualitatively similar to the effect of the ASA treatment, which resulted in a $125 \%$ increase in bleeding time compared to the vehicle group (Fig. 1). The increased bleeding times associated with the ASA and TIE groups provide evidence of the antithrombotic effect of these treatments. Results of the bleeding time tests are shown in Table 3.

\section{Survival rate}

TIE-treated experimental group had increased the survival rate in mice. TIE had the same result with ASA from $100 \%$ induction of collagenepinephrine inhibited at doses 2 and 3 . The survival rate calculation results were shown in Table 4.

\section{Discussion}

\section{Analysis of total flavonoid and phenolic content}

Tamarind extract has a low flavonoid content. The sample used in this study had no detectable phenolic content. Flavonoid compounds play a role as antioxidants and also function as antithrombotic agents by reducing adenosine diphosphate (ADP)-induced aggregation and thrombin. Specifically, flavonoids act as TxA2 receptor antagonists, reducing TxA2 which then indirectly inhibits COX-1. In addition, flavonoid compounds increase the production of nitric oxide, which is important for the inhibition of platelet aggregation [16].

\section{Analysis of bleeding time}

The antithrombotic effect of TIE was evaluated by comparing the bleeding time of treated animals to animals in the vehicle group. Treatments with TIE, which contains the D-003 compound dotriacontanoic acid, resulted in significant, dose-dependent increases in bleeding time. However, the bleeding times of the TIE-treated animals were not significantly different from those of ASA-treated animals, indicating that the antithrombotic effect was the same for both groups. The largest bleeding time effect was seen in the experimental group given the highest dose of TIE ( $56 \mathrm{mg} / 20 \mathrm{~g}$ mice)

Inhibition of platelet aggregation includes the reduction of TxA2 formation and prostacyclin (PgI2) enhancement. TxA2 is a potent agonist causing the activation of platelets and thrombus formation. TxA2 causes irreversible platelet aggregation, vasoconstriction, and proliferation of smooth muscle cells [17]. PgI2 is synthesized by PgI2synthase in endothelial cells and has an effect as an aggregation inhibitor and vasodilator. PgI2 acts to inhibit vasoconstriction and dilate blood vessels [8]. When the formation of the thrombus is inhibited, blood flow is smooth and bleeding times increase.

In this study, the antithrombotic effects of TIE treatments were similar to that of the aspirin treatment. Aspirin inhibits collagen-induced platelet aggregation at optimal doses of 81-162 mg/day [18]. Aspirin works as an antithrombotic agent by inhibiting the enzyme COX and non-COX inhibition. Inhibition of COX-1 will inhibit TxA2 formation and stimulate platelet aggregation. In non-COX enzymes, aspirin will alter glycoprotein IIb/IIIa receptor function and affect the permeability of clots. In addition, aspirin also inhibits acetylates, prothrombin, antithrombin, fibrinogen, and factor XIII [18]. 


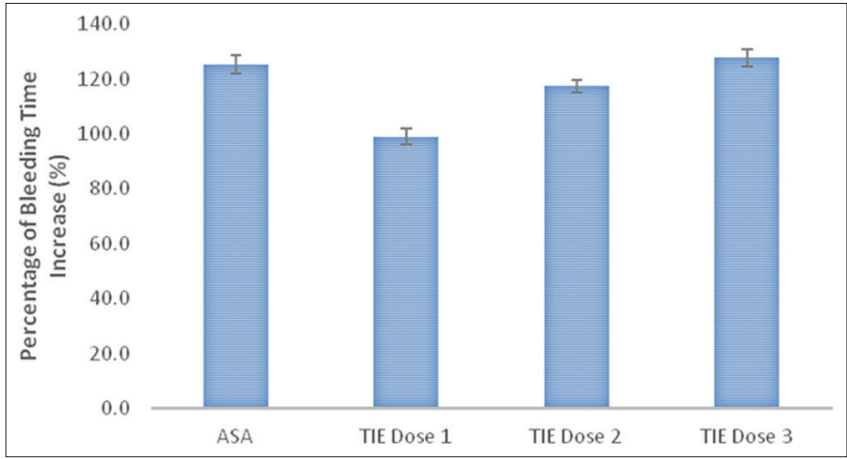

Fig. 1: The proportional increase in bleeding time across experimental treatment groups, as compared with the normal control group

Table 3: Results of bleeding time tests

\begin{tabular}{ll}
\hline Group & Bleeding time (mean \pm SD) \\
\cline { 2 - 2 } & TIE \\
\hline Normal & $7.32 \pm 1.10$ \\
ASA & $16.50 \pm 3.24^{*}$ \\
Dose 1 & $14.56 \pm 3.02^{*}$ \\
Dose 2 & $15.92 \pm 2.01^{*}$ \\
Dose 3 & $16.68 \pm 3.21^{*}$ \\
\hline
\end{tabular}

Normal (CMC 0.5\% volume: $0.3 \mathrm{ml} / 20 \mathrm{~g} \mathrm{BW}$ ), ASA (aspirin

$0.208 \mathrm{mg} / 20 \mathrm{~g} \mathrm{BW}$ ), Dose 1 (14 mg/20 g BW), Dose 2 (28 mg/20g BW),

Dose $3(56 \mathrm{mg} / 20 \mathrm{~g} \mathrm{BW}) .{ }^{*} \mathrm{p} \leq 0.05$, compared with the normal control group.

CMC: Carboxymethyl cellulose, ASA: Acetylsalicylic acid, BW: Bodyweight,

SD: Standard deviation

Table 4: Survival rates within experimental treatment groups

\begin{tabular}{ll}
\hline Group & Survival rate (\%) \\
\cline { 2 - 2 } & TIE \\
\hline Normal & - \\
Negative & 0 \\
ASA & 100 \\
Dose 1 & 80 \\
Dose 2 & 100 \\
Dose 3 & 100 \\
\hline
\end{tabular}

Normal (CMC 0.5\% volume: $0.3 \mathrm{ml} / 20 \mathrm{~g} \mathrm{BW}$ ), ASA (aspirin $0.208 \mathrm{mg} / 20 \mathrm{~g} \mathrm{BW}$ ), Dose 1 (14 mg/20 g BW), Dose 2 ( $28 \mathrm{mg} / 20 \mathrm{~g}$ BW), Dose $3(56 \mathrm{mg} / 20 \mathrm{~g} \mathrm{BW}$ ).

CMC: Carboxymethyl cellulose, ASA: Acetylsalicylic acid, BW: Bodyweight, TIE: Tamarindus indica L. extract

\section{Analysis of survival rate}

A combination of collagen and epinephrine was used to induce thrombosis in the experimental animals. Collagen is a major activator of secreting granules (serotonin and ADP) which, in turn, activate platelets to attach to the subendothelial and form aggregates $[12,19]$. Epinephrine can cause platelet aggregation induced by ADP. Epinephrine is an $\beta 2$-adrenergic agonist which causes a disruption of the exchange between potassium ions and sodium and calcium ions, leading to hypokalemia [20,21]. Hypokalemia causes stimulation of the muscle membrane to be disrupted which can lead to paralysis [22]. The injections of collagen and epinephrine caused the deadly effects in mice through thromboembolism or vasoconstriction by increased TxA2 and Pgs from platelets [17].

The active antithrombotic compound within TIE, the D-003 compound dotriacontanoic acid, can inhibit platelet aggregation induced by collagen-epinephrine. The D-003 compound inhibits platelet aggregation induced by collagen, arachidonic acid, serotonin, and ADP $[23,24]$. In addition, the D-003 compound also inhibits platelet aggregation induced by a combination of collagen and epinephrine [8]. Prior studies have found that treatment with D-003 inhibits platelet aggregation by $55 \%$ at a dose of $400 \mathrm{mg} / \mathrm{kg}$ BW of mice [8]. The dotriacontanoic acid compound (D-003) can also significantly increase the survival rate in a dose-dependent manner. TIE is more effective at inhibiting platelet aggregation induced by collagen-epinephrine than aggregation that is induced by ADP. A prior study, involving treatment with the D-003 compound at a dose of $200 \mathrm{mg} / \mathrm{kg}$ BW of mice, documented that D-003 resulted in a 33\% inhibition of ADP-induced platelet aggregation and a 39\% inhibition of aggregation induced by collagen-epinephrine [8].

\section{CONCLUSION}

Using in vivo experiments, we demonstrated that TIE has antithrombotic potency evidenced by increasing bleeding times and survival rates in TIE-treated experimental animals. The greatest antithrombotic potency was found at a dose of $56 \mathrm{mg} / 20 \mathrm{~g}$ mice.

\section{ACKNOWLEDGMENT}

This research was supported by Faculty of Pharmacy, Universitas Indonesia, and funded by Directorate of Research and Community Engagement (PITTA grant 2018), Universitas Indonesia.

\section{CONFLICTS OF INTEREST}

All authors have none to declare.

\section{REFERENCES}

1. Liu X, Hao J, Shan X, Zhang X, Zhao X, Li Q, et al. Antithrombotic activities of fucosylated chondroitin sulfates and their depolymerized fragments from two sea cucumbers. Carbohydr Polym 2016;152:343-50.

2. Daykin HJ, Sturgeon SA, Jones C, Wright CE. Arterial antithrombotic effects of aspirin, heparin, enoxaparin and clopidogrel alone, or in combination, in the rat. Thromb Res 2006;118:755-62.

3. Bassi B, Nickels LC, Flach FE, Deportu G, Ganti L. Case report acute on chronic venous thromboembolism on therapeutic anticoagulation. Case Rep Emerg Med 2013;2013:295261.

4. Ayanbule F, Li G, Peng L, Nowicki J, Anderson G. Anti-jugular vein thrombotic effect of Morinda citrifolia L. [Noni] in male SD rats. Funct Foods Heal Dis 2011;1:297-309.

5. Viswanatha GL, Rafiq M, Rajesh S, Sandeep Rao KS, Azeemuddin M, Anturlikar SD. et al. Anti-platelet and anti-thrombotic effects of a polyingredient formulation: In vitro and in vivo experimental evidences. Oman Med J 2012;27:e010.

6. Chelucci RC, Dutra LA, Lopes Pires ME, de Melo TR, Bosquesi PL, Chung MC, et al. Antiplatelet and antithrombotic activities of nonsteroidal anti-inflammatory drugs containing an $\mathrm{N}$-acyl hydrazone subunit. Molecules 2014;19:2089-99.

7. Shaikh, W. Chemical constituents of Tamarindus indica L. Pharmacogn Rev 2008;40:2553-9.

8. Molina V, Arruzazabala ML, Carbajal D, Más R. D-003, a potential antithrombotic compound isolated from sugar cane wax with effects on arachidonic acid metabolites. Prostaglandins Leukot Essent Fatty Acids 2002;67:19-24.

9. Ara N, Islam M. Phytochemical screening and in vitro antibacterial activity of Tamarindus indica seeds ethanolic extract. Curr Trends Biotechnol Pharm 2009;26:19-23.

10. Atanassova M, Georgieva S, Ivancheva K. Total phenolic and total flavonoid contents, antioxidant capacity and biological contaminants in medicinal herbs. Ivancheva J Univ Chem Technol Metall 2011;46:81-8.

11. Ikram EH, Eng KH, Jalil AM, Ismail A, Idris S, Azlan A, et al. Antioxidant capacity and total phenolic content of Malaysian underutilized fruits. J Food Compos Anal 2009;22:388-93.

12. Saputri FC, Nabila N, Mun'im A. Combination of ginger and sappan wood extract effect on in vivo antithrombotic activity test. J Young Pharm 2017;9:46-8.

13. Liu Y, Jennings NL, Dart AM, Du XJ. Standardizing a simpler, more sensitive and accurate tail bleeding assay in mice. World J Exp Med 2012;2:30-6.

14. Warner TD, Nylander S, Whatling C. Anti-platelet therapy: Cyclooxygenase inhibition and the use of aspirin with particular regard to dual anti-platelet therapy. Br J Clin Pharmacol 2011;72:619-33. 
15. Lee J, Park DH, Jung SH, Lee S, Oak M. The antithrombotic activity of ethanol extract of Lysimachia clethroides. J Korean Soc Appl Biol Chem 2010;53:384-5.

16. Faggio C, Sureda A, Morabito S, Sanches-Silva A, Mocan A, Nabavi SF, et al. Flavonoids and platelet aggregation: A brief review. Eur J Pharmacol 2017;807:91-101.

17. Huang J, Wang S, Luo X, Xie Y, Shi X. Cinnamaldehyde reduction of platelet aggregation and thrombosis in rodents. Thromb Res 2007:119:337-42.

18. Gurbel PA, Bliden KP, DiChiara J, Newcomer J, Weng W, Neerchal NK, et al. Evaluation of dose-related effects of aspirin on platelet function: Results from the aspirin-induced platelet effect (ASPECT) study. Circulation 2007; 115:3156-64.

19. Raghavendra RH, Naidu KA. Spice active principles as the inhibitors of human platelet aggregation and thromboxane biosynthesis. Prostaglandins Leukot Essent Fatty Acids 2009;81:73-8.

20. Barisione G, Baroffio M, Crimi E, Brusasco V. Beta-adrenergic agonists. Pharmaceuticals (Basel) 2010;3:1016-44

21. Cheng CJ, Kuo E, Huang CL. Extracellular potassium homeostasis: Insights from hypokalemic periodic paralysis. Semin Nephrol 2013;33:237-47.

22. Abbas H, Kothari N, Bogra J. Hypokalemic periodic paralysis. Natl J Maxillofac Surg 2012;3:220-1.

23. Molina V, Arruzazabala ML, Carbajal D, Más R, Valdés S. Antiplatelet and antithrombotic effect of D-003. Pharmacol Res 2000;42:137-43.

24. Molina V, Arruzazabala ML, Carbajal D, Más R. Synergistic effect of D-003 and aspirin on experimental thrombosis models. Prostaglandins Leukot Essent Fatty Acids 2003;68:305-10 